\title{
Investigating the deterioration of an industrial heritage structure
}

\begin{abstract}
Conservation and rehabilitation of heritage structures has turned into a prime concern in historically enriched countries, especially in developed societies. Modern technologically advanced societies often wish to keep and maintain the remains of architectural heritage sites and pass the essence of these tangible and intangible cultural values to future generations. The present study introduces a historical industrial structure in Guimarães, Portugal which was once renowned as part of the leather industry but has now been dilapidated for many years. As part of the city authorityô plan to regenerate the whole town, this industrial heritage structure needs to be rehabilitated. This study presents an intensive structural survey with conventional non-destructive tests (NDT). Visual survey was used to attempt to identify problems in the structure and their possible decay mechanisms. Damages to the building include the decay of timber and stones, dampness problems and incompatible structural assemblage. The lack of long-term maintenance is one of the potential causes which has aggravated decay. NDTs were utilised to characterise the basic mechanical properties of the deteriorated timber elements. The findings allowed the safety of this industrial heritage structure to be appraised which could be beneficial for the conservation management plan of this city.
\end{abstract}

Keyword: Cultural heritage; Damage mechanism; Structural cracks; Non-destructive test; NDT 